\title{
BASES DE LAS RELACIONES LABORALES: PERSPECTIVAS EN EL SALVADOR
}

\author{
Louis Gérard Dennery*
}

L

as personas son esenciales para la eficiencia y eficacia de una organización; necesariamente surgen entre los recursos dependencia, de subordinación, de dirección y colaboración, que al mismo tiempo generan tensiones que llevan a enfrentarse a conflictos entre grupos e individuos que entran en competencia; estas relaciones exigen decisiones difíciles que afectan a la Dirección y el Control y a todas las variables dependientes del comportamiento organizacional, tales como: la productividad, la rotación del personal, el ausentismo, las huelgas, los paros, el tortuguismo, la satisfacción o insatisfacción, etc.

Para lograr armonizar los intereses tanto de patronos como de trabajadores, se han sentado algunas bases sobre las cuales descansan las relaciones laborales:

I. Instrumentos legales

- Contrato individual

- Contrato colectivo

- Reglamento interno de trabajo

- Proceso de quejas

- Catedrático del Departamento de Administración de Empresas de la UCA 
II. Nuevas formas de negociación

- Negociación en base a posiciones

- Negociación en base a intereses

III.Estilos gerenciales

- Dirección científica

- Dirección de rol o de papeles

- Dirección participativa

IV. Otras tendencias filosóficas y gerenciales

- Solidarismo

- Salarios participativos.

V. Perspectivas de las relaciones laborales en el sector público.

\section{Instrumentos legales}

T a legislación laboral tiene por objeto principal armonizar las $\amalg$ relaciones entre el capital y el trabajo, independientemente de la forma que adopten las empresas del sector privado, excluyendo inicialmente ciertas instituciones del sector público como: las fuerzas armadas, la policía y los funcionarios de alto nivel del Estado; sin embargo indica la gran importancia de la participación del gobierno en el proceso de los contratos colectivos, tal como quedó demostrado en el Foro de Concertación Económica y Social.

- Contrato individual de trabajo. "Es aquel en virtud del cual una o varias personas se obligan a ejecutar una obra o a prestar un servicio, a uno o varios patronos, institución, entidad o comunidad de cualquier clase, bajo la dependencia de éstos y mediante un salario". Da estabilidad y seguridad al trabajador, a pesar de que suele estipularse que los primeros 30 días sean de prueba; contiene además tanto las obligaciones y prohibiciones de los patronos como de los trabajadores; considera también el Código de Trabajo, la interrupción, resolución, terminación de contrato y la indemnización por despido, los salarios mínimos, las jornadas de trabajo, descansos y otras prestaciones como: vacaciones, asuetos, aguinaldos...

- Contrato colectivo de trabajo. Los trabajadores tienen derecho de asociarse libremente, principio de autonomía sindical, para defender sus intereses económicos y sociales comunes. Esta indepen- 
dencia requiere por lo tanto de ciertas condiciones y libertades de:

- Reglamentación

- Representación

- Gestión

- Suspensión y disolución

- Federación y confederación

Pero también tienen ciertas limitaciones de orden: Legal y administrativo. Por ejemplo de carácter legal: Constitución de los sindicatos. Antepropuesta hecha por la Organización Internacional del Trabajo (O.I.T.) a los artículos 211 y 248 en el sentido de rebajar a 25 el número mínimo de miembros para la constitución de un sindicato y la protección que los fundadores de estos sindicatos deben tener desde el momento en que se presentan ante la autoridad respectiva con el objeto de registrarlo. Es así, de acuerdo con las reformas se reconocerán las siguientes clases de sindicatos:

- Sindicato de gremio

- Sindicato de empresa

- Sindicato de industria

- Sindicato de empresas varias

- Sindicato de trabajadores independientes.

Sin embargo, tendrán prohibido limitar la libertad de trabajo de los no afiliados, coaccionar a éstos para que ingresen al sindicato y a los afiliados para que no se retiren del mismo. Por ejemplo de carácter administrativo. (Gobierno de los sindicatos). Para constituirse, tiene que estar presente un notario o un delegado del ministerio de Trabajo y contener ciertos programas de acción, con financiamiento propio y fondos de reserva o con la posibilidad de contratar obligaciones con terceros.

- Contrato colectivo de trabajo. "Se celebra entre uno o varios sindicatos de trabajadores" por una parte y un patrono por la otra". El sindicato de trabajadores es el titular de los derechos de celebrar y revisar un contrato colectivo. Contiene los derechos y obligaciones de las partes contratantes y cláusulas que garanticen su ejecución y vigencia.

La sindicalización como concepción filosófica de las relaciones laborales, nace de la necesidad de responder con eficacia a los angustiantes problemas sociales y económicos de los trabajadores. 
Supone la existencia de un enfrentamiento entre explotadores y explotados; algunos dirigentes sindicales perciben las relaciones laborales como un conflicto, como una pugna de clases; por lo tanto el sindicato facilita lograr metas y condiciones de vida más humanas tales como:

- El reconocimiento y respeto de otros.

- Cierto grado de comodidad y seguridad económica.

Toda afiliación a un sindicato no es más que una forma defensiva y un esfuerzo para aumentar la satisfacción de necesidades sociales y económicas. Cuando un sindicato está reconocido y legitimado, es representante de los trabajadores de la empresa para: negociar el contrato colectivo de trabajo y para: enfrentar y solucionar los problemas de sus agremiados en la organización.

\section{Contenido del contrato colectivo}

- Reconocimiento del sindicato y seguridad sindical.

- Lugar y fecha de su otorgamiento.

- Propósito e intención de las partes.

- Alcance del contrato (fecha en que entrará en vigor y su duración).

- Condiciones generales de trabajo que regirán los contratos individuales celebrados en las empresas. (Parte normativa).

- Derechos y obligaciones de las partes contratantes acerca de casos de suspensión, disciplina, despidos, huelgas, paros, manejo y arbitraje de queja, salarios, pagos, horarios, tiempo extra, días festivos, vacaciones, antigüedad, seguridad e higiene, prestaciones complementarias... (elemento obligatorio).

- Reglamento interno del trabajo. "Todo patrono privado que ocupe de modo permanente 106 más trabajadores, tienen la obligación de elaborar un reglamento interno de trabajo, que deberán someter a la aprobación del Director General de Trabajo".

Deberá considerar los requisitos de ingreso a la empresa, horarios de trabajo, de comidas, pago de salarios, descansos asuetos y vacaciones, aguinaldos, derecho y obligaciones de los trabajadores y empresarios, labores que no deben ejecutar mujeres ni menores 
de edad, examen médico y medidas profiláctica, seguridad, higiene en el lugar de trabajo, peticiones, reclamos y modo de resolverlos, disposiciones disciplinarias y modos de aplicar.

Se recomienda que las sanciones que deban imponerse por infracciones específicas, tienen que ser lo suficientemente concretos y acordes con el Código de Trabajo vigente y seguir una política disciplinaria progresiva, en la que la gravedad de la sanción aumente con cada infracción subsiguiente; además, antes de tomar una acción disciplinaria contra un trabajador, debe entrevistársele (derecho de apelación), con el propósito de solicitar información que pueda revelar actitudes, comportamiento y otras razones concurrentes a causar una infracción; debe mantenerse en el archivo personal, expediente del trabajador, un registro de la ofensas en que ha incurrido y las acciones disciplinarias de que ha sido objeto, incluyendo las reprimendas formales.

En síntesis que se elabore el Reglamento de Trabajo en equipo en el cual un coordinador que lo redacte y tome en cuenta las razones del patrono, jefes, algunos trabajadores especializados, a efecto de que este instrumento legal facilite el funcionamiento del contrato de trabajo y las relaciones interpersonales y empresariales.

- Proceso de quejas. La disciplina y las quejas son sólo 2 de las principales áreas del proceso de administración de contratos; los problemas disciplinarios constituyen la mayoría de los casos de quejas de todos los niveles de la estructura organizacional.

La queja es toda manifestación de inconformidad por parte de un subordinado, debido generalmente a problemas de relaciones interpersonales, grupales y de trabajo. Por lo tanto es necesario establecer un procedimiento para recibir las quejas y al mismo tiempo resolverlas; sirven además para evaluar y diagnosticar el clima laboral y de la organización.

Proceso. Probablemente no existe un procedimiento único de quejas, porque los sistemas formales varían de una empresa a otra, por su tamaño, la calidad de la fuerza laboral, el estilo de liderazgo, la filosofía gerencial y administrativa. La queja puede hacerse en forma oral, verbal o escrita; para su conformación, presenta 3 etapas, a saber: 
- Inconformidad - aquella circunstancia que da lugar al malestar del trabajador.

- Queja - es la manifestación oral o escrita del malestar, de la inconformidad.

- Agravio - es cuando la queja no ha sido resuelta por la empresa y el trabajador sigue insatisfecho.

Ahora un proceso simplificado de quejas, puede constar de estos 4 pasos:

\section{Pasos Representante laboral}

1. Trabajador o secretario sindical

2. Encargado de quejas

3. Comité de quejas de la empresa

4. Arbitraje (mediación)

\section{Representante patronal}

Jefe inmediato del trabajador (Supervisor).

Jefe depto. o superior del Supervisor.

Gerente de la División de R. Humanos.

Gerente general.

\section{Nuevas formas de negociación.}

$\mathrm{Z}^{1}$ acelerar la generación de empleo, requiere respetar el dere cho de las partes a defender sus intereses por medio de la negociación colectiva y además reconocer el derecho de los trabajadores a organizarse en sindicatos y superar la tendencia "científica" obsoleta de considerar el recurso humano como un simple factor de producción. El convenio 87 de la O.I.T. (Organización Internacional del Trabajo), parte primera, menciona en su artículo 2: "Los trabajadores y los empleadores, sin ninguna distinción, y sin autorización previa, tienen el derecho de constituir las organizaciones que estimen convenientes, así como el de afiliarse a estas organizaciones, con la sola condición de observar los estatutos de las mismas".

\section{Métodos de negociar:}

Son procesos de resolución de problemas, siguiendo ciertos prin cipios, para llegar a soluciones efectivas y mejorar a la vez, las relaciones obrero empresariales. 
- Punto de partida = No se basa en posiciones como tradicionalmente se da, sino en intereses.

- Estrategia $=$ No consiste en hacer ajustes graduales a las posiciones, sino en elaborar alternativas en forma conjunta.

- Solución = Se usan pautas para analizar y evaluar alternativas y se decide por consenso.

Entre las estrategias de negociación se tiene: Atacar el problema, concentrarse en el tema de negociación, no en las personas para desacreditarlas, ni en su pasado; explorar en esta etapa inicial, todos los intereses para definir con claridad el problema.

\section{Etapas en las negociaciones en base a intereses}

T as cuatro etapas son las mismas en los dos tipos de negocia$\checkmark$ ciones: Tradicional y en base a intereses.

1. Preparación para las negociaciones, intercambiar listas de problemas antes de las negociaciones para que tengan ambas partes tiempo para preparar intereses sobre todos los asuntos y acordar establecer las reglas de juego.

2. Apertura de las negociaciones. Se firma el compromiso mutuo, aclarando y definiendo el alcance de los temas.

3. Negociación aplicando el proceso de resolución de problemas.

- Se desplega y revisa todos los intereses, identificando intereses comunes y generando opciones a través del "Brain Storming" (Lluvia de ideas).

- Se establecen pautas, normas y se evalúa cada opción en base a documentación escrita, código de trabajo y se llega a un consenso acerca de la solución.

- Deben estar abiertos a propuestas, alternativas, posibilidades y no insistir en su posición, en la solución propuesta.

- Deben ayudar a satisfacer deseos de ambas partes y todos los intereses propios y los intereses que las dos partes tienen en común. 
- Se debe adoptar una solución en forma mutua, la alternativa más apropiada, usando pautas y no presionando para conseguir su propuesta de alternativa; la solución debe ser un acuerdo negociado que resulte de un proceso en base a intereses.

Sustentan el proceso de negociación las formas como los negociadores actúan entre sí:

- Concentrarse en el problema.

- Explorar todos los intereses relacionados con el problema.

- Ser abierto y receptivo a ideas y alternativas

- Satisfacer intereses comunes.

- Usar políticas y normas acordadas previamente para llegar a solución factible de implantarse y se nombra una comisión para la redacción de esta solución.

4. Comunicación de los resultados a los grupos representados y preparación de una declaración conjunta.

\section{Estilos gerenciales}

T a empresa se constituye actualmente a partir de las necesida Ldes de la población y tiene como finalidad principal, producir y ofrecer bienes y servicios destinados a satisfacer las metas de la sociedad y la obtención de beneficios para:

- Los accionistas o propietarios, quienes aportan los recursos financieros.

- Los trabajadores, quienes aportan la mano de obra.

Así cualquier gerente tiene 2 compromisos inviolables: Conseguir un beneficio atractivo para los accionistas y proporcionar atractivas oportunidades de trabajo a los empleados.

Nos referiremos a 3 estilos de dirección que nos permite cumplir estos compromisos.

1. Científico.

2. De papeles o roles.

3. Participativa. 


\section{Dirección científica}

F $n$ El Salvador, se reflejan en una dirección científica las carac terísticas predominantes de la cultura organizacional, donde la misión empresarial se identifica en todo aquello que manda el jefe, en el poder del dueño, quien cree que el hombre es una máquina que produce y cuyo salario es el único factor de motivación; donde los valores culturales son los de: dependencia, obediencia, docilidad, lealtad, control personalizado; donde los poderosos protegen a los débiles y se responsabilizan de éstos, exigiendo a las personas de niveles inferiores; fuerte autoridad sin discusión, refuerzo del "Staff" versus la línea. En pocas palabras, burocracia, basada en la jerarquización, reglas y procedimientos, especialización impersonalidad.

\section{Dirección de papeles o roles}

in embargo, en algunas empresas, debido a su misma comple jidad estructural, tecnológica, la gestión administrativa empieza a cambiar, adquiriendo nuevos rumbos, orientados hacia una dirección de papeles. Los resultados se fundamentan en el conocimiento del rol que se desempeña dentro de la empresa y de las responsabilidades inherentes del puesto de trabajo, donde los valores técnicos, las habilidades del experto son imprescindibles, donde las actitudes son las de dedicación absoluta, de sentido de identificación y permanencia; el control impersonal se impone por los contratos; implica orden, racionalidad, rigidez, preocupación excesiva por el buen funcionamiento, cumplimiento de las normas. En mi criterio, en El Salvador, se requiere que el estilo gerencial evolucione, cambie, para que las empresas puedan competir; cambiar el entorno, las relaciones interpersonales y grupales, la cultura y mentalidad, mejorar la calidad de las comunicaciones, los conocimientos y actitudes de los directivos empresariales y sindicales; terminar con la dependencia de la inspección; crear un sistema donde las máquinas y equipos informaticos, los hombres motivados, se combinen en una estructura que facilite su óptima utilización y productividad.

\section{Dirección participativa}

Dor lo tanto, ahora que se habla de reconversión industrial, se deberá adoptar un estilo de dirección participativa, donde la misión empresarial reside en el cumplimiento de la palabra, en la 
delegación, la ayuda interpersonal, el solidarismo; donde las actitudes son de confianza, de armonía, en base a intereses comunes, de desarrollo de las personas, de decisiones consensuadas que crean y mantengan este clima de confianza; nadie puede rendir su máximo, si sigue siendo desconfiado, inseguro.

En esta nueva situación, las organizaciones están obligadas a cuidar sus miembros más allá del contrato laboral. Las empresas efectivas, competitivas, deberán ser suficientemente flexibles para adecuar sus estructuras a los nuevos desafíos y necesidades que plantea el entorno; optimizar el uso de todos sus recursos y especialmente su fuerza de trabajo a través de relaciones, esfuerzos conjuntos y del entrenamiento.

En este nuevo escenario, el mejor involucramiento del trabajador, es imprescindible; los equipos de trabajo "task force", adquieren cierta autonomía e iniciativa para planificar, organizar, ejecutar y controlar lo que se va hacer, cambiando así el papel del supervisor, quien pasa a ser un asesor que aporta nuevos sistemas y técnicas para mejorar el trabajo.

Entonces ¿por qué deben cambiar los estilos gerenciales y las relaciones laborales?

Deben cambiar para:

- Lograr mayor productividad en base a cooperación, intereses comunes entre empresarios y trabajadores.

- Lograr mayor competitividad, satisfaciendo las necesidades tanto del mercado interno como otros mercados.

Así el comportamiento organizacional, fruto de las relaciones obrero-patronales, deberá cimentarse sobre principios tales como:

- Visión común, objetivos e intereses comunes.

- Responsabilidad y beneficios conjuntos.

- Resolución de problemas en conjunto e involucramiento del trabajador.

- Creación de comités mixtos (círculos de calidad, grupos de tareas, comité obrero=patronal).

- Negociación en base a intereses. 


\section{Otras tendencias filosóficas y gerenciales}

\section{* Solidarismo}

T a conjugación de intereses entre patrono y trabajador através Le una comunicación efectiva y un marco económico-social, constituyen algunos principios filosóficos del movimiento solidarista. Reconoce esta tendencia, la relación de interdependencia entre trabajadores y empresarios; promueve una estrecha vinculación entre la parte laboral y administrativa, de tal manera que de la cooperación y la producción derivada puedan obtenerse ganancias que posibiliten el acceso de los trabajadores a los medios de producción. Propugna la propiedad privada como medio de seguridad y como incentivo para el incremento de la producción, pero a la vez, busca los mecanismos para que los trabajadores puedan tener participación en la tenencia del capital y en la gestión de las empresas.

\section{Algunos objetivos del movimiento solidarista son:}

- Fortalecer las relaciones de solidaridad, buena voluntad entre los trabajadores y patronos.

- Despertar la conciencia social, para mayor justicia y mejor entendimiento.

- Fomentar la productividad y el rendimiento de la empresa para beneficio de todos.

- Procurar la creación de nuevas empresas con participación laboral como recurso de distribución.

- Llegar a tener un capital con ahorro de todos y con participación de la empresa.

La principal característica del solidarismo es que reconoce la interdependencia de los factores que integran la producción y en consecuencia, deben éstos factores operar en cooperación; crear condiciones que permitan una mayor participación de los trabajadores en los beneficios derivados de la producción de riqueza es especialmente importante, cuando nuestras economías se enfrentan al reto de la reconversión industrial, en la que la creatividad, competitividad, calidad de mano de obra son componentes esenciales. 
T a modernización de las relaciones laborales dentro de la em Lpresa y el paso de la confrontación a la colaboración abarcan muchos elementos, entre los cuales resalta el concepto de participación en programas de entrenamiento, de círculos de calidad y productividad; pero su área básica, gira alrededor de mecanismos tendientes a ligar la producción con incrementos en el nivel de los salarios; entre dichos mecanismos se desprende la participación en los resultados financieros de la empresa o salarios participativos. Lo anterior no sólo mejora el rendimiento sino que refuerza y acelera las fuerzas del mercado, conducente al pleno empleo productivo.

De hecho, actualmente predomina la forma de estipulación de salarios por Unidad de tiempo: "es cuando el salario se paga ajustándolo a unidades de tiempo, sin consideración especial al resultado del trabajo"; por ejemplo el salario mínimo, o salario básico por hora, convenido por día, dividido entre el número de horas de que consta la jornada ordinaria de trabajo ( $\$ 930$ mensuales dividido entre 30 días, resulta $₫ 31$ diarios; entre 8 horas de trabajo diario: $\$ 3.875$ por hora). Otras formas de estipulación de salarios son: por unidad de cbra, cuando se toma en cuenta la cantidad de unidades producidas, independientemente del tiempo invertido; por sistema mixto, en el cual se paga tanto volumen como tiempo; por tarea, cuando el trabajador se obliga a realizar una obra en un período de tiempo convenido; por comisión sobre todo en el caso de los vendedores; por ajuste o precio alzado: Aquí el salario se pacta en forma global. En estas formas anteriores de salarios, casi no se consideran el esfuerzo del trabajador ni su rendimiento; de ahí que el empleado tenga poco incentivo para innovar o para aumentar su nivel de activación. Se sugiere que pagar de acuerdo con el rendimiento puede elevar la productividad de la mano de obra, sin esfuerzos adicionales de inversión en recursos materiales, humanos y tecnológicos. Recientes estudios han demostrado que la participación de los salarios en los resultados, redunda en un aumento en la productividad, del orden del $6 \%$ al $8 \%$, efecto que se acentúa si los trabajadores tienen ingerencia o son consultados en las gestiones diarias de la planta; además al identificar los intereses de los operarios con los resultados de la organización y vice- 
versa, suele mejorar también el clima de las relaciones laborales; por otra parte, el hecho de que el salario no sea fijo (salario mínimo), sino que dependa del rendimiento de la mano de obra, de los ingresos de la empresa en concepto de ventas, sus utilidades, el valor de la producción..., estimula la organización a expandir la contratación. El aspecto negativo de esta forma de estipulación de salarios, es que el ingreso de los trabajadores es variable, inestable. De todos modos, es importante que la mano de obra conozca, discuta y determine junto con los empresarios (la administración), el sistema de pago, pues si es impuesto y complejo, puede carecer de credibilidad. Los sectores productivos y de servicios, deberían fomentar el sistema de salarios participativos y sobre todo dar acceso a los trabajadores a la propiedad accionaria.

\section{Perspectivas de las relaciones laborales en el sector público}

T a propuesta de reformas a la Constitución Política presentada Lpor el gremio de trabajadores que afectaba los artículos 47 y 221 y permitía la libre sindicalización y el derecho a huelga de los trabajadores del Estado, no fue aprobada por la Asamblea; según una sindicalista: se ha negado al trabajador sus derechos, pues con esta propuesta lo que se busca son mecanismos de concertación y no de confrontación; según por otro lado, el presidente de la Asamblea: el que quiere hacer huelga, se puede ir a la empresa privada donde hay sindicatos establecidos, el que acepta trabajar con el gobierno, sabe que no hay huelga.

Sin embargo, ante estas dos posiciones contradictorias, para un futuro a largo plazo, lograda constituirse una mesa de negociación en los que estén presente los delegados de la Administración Pública y las organizaciones sindicales son representativas a nivel estatal y de comunidad autónoma, deberán incluir en el análisis y determinación de las condiciones de trabajo, algunos de los sectores específicos que a continuación se enumeran:

- Personal docente de centros educativos públicos (educación).

- Personal al servicio de las instituciones sanitarias públicas (salud).

- Personal de la Administración Central, Instituciones y de las entidades gestoras de la seguridad social (I.S.S.S., I.N.P.E.P.). 
- Personal de la Administración de Infraestructuras Públicas (Obras Públicas).

- Personal al servicio de las municipalidades.

- Personal al servicio de la hacienda pública.

Podrán ser objeto de negociación en su ámbito respectivo y en relación con las competencias de cada sector de la administración pública los aspectos siguientes:

- Determinación y aplicación de sueldos y salarios de los trabajadores del Estado.

- Incremento de remuneraciones, incluido en el proyecto de presupuestos.

- Análisis, descripción y clasificación de cargos.

- Preparación y diseño de los planes de oferta de empleo estatal.

- Planeamiento cuantitativo y cualitativo de los recursos humanos del gobierno (carrera administrativa).

- Elaboración de programas de entrenamiento y políticas para la administración de las principales acciones de personal como: nombramiento, promoción, transferencia, amonestación...

- Determinación de las prestaciones y pensiones de las clases pasivas.

- Medidas sobre salud laboral y condiciones de trabajo de los funcionarios públicos.

Quedarán excluidas de la obligatoriedad de la negociación, todas las decisiones de las administraciones públicas, que afectan a sus potestades de organización, al ejercicio del derecho de los ciudadanos ante los funcionarios públicos y al procedimiento de formación de los actos y disposiciones administrativas.

Desaparece el Foro de concertación Económica y Social con la creación del Consejo Superior del Trabajo en el cual estará representada la empresa privada, los trabajadores y el gobierno. Sobre la ley que permitiría la sindicalización de los empleados públicos, un prominente empresario salvadoreño afirmó que no se hará porque es una situación inconstitucional. Sin embargo, la empresa privada, considera el recién aprobado Código de Trabajo como un 
"paso para armonizar las relaciones obrero-patronal".

\section{Referencias:}

- Código de Trabajo. El Salvador.

- Equidad y transformación productiva: "Un enfoque integrado", capítulo IV. Ingreso y productividad del trabajo. CEPAL. Santiago de Chile, 1992.

- Taller regional, sobre nuevas formas de cooperación obrero-patronales. A.I.D., Costa Rica 1994.

- Ley de Asociaciones Solidaristas.

- Arenilla, S. Manuel. La negociación colectiva de los funcionarios públicos.

- Davis, Keith y Werther, William. Administración de personal y recursos humanos. 3ra. Edición, McGraw Hill.

- Chiavenato, Idalberto. Administración de recursos humanos.

- Chaudeny Sherman - Administración de personal. Grupo editorial Hiberoamérica. 